\title{
LA EXPERIENCIA ONÍRICA EN LA LITERATURA INFANTIL Y JUVENIL DE ROSA MONTERO
}

\author{
Eva María VILLAR SECANELLA \\ Universidad de Zaragoza \\ evillar@unizar.es
}

Resumen: Este artículo analiza el discurso narrativo de la trilogía de Rosa Montero, destinada a un público infantil y juvenil: Las barbaridades de Bárbara, El viaje fantástico de Bárbara y Bárbara contra el Doctor Colmillos. El fin de esta investigación es determinar las estrategias discursivas utilizadas en estas tres obras donde viajar, la aventura exterior de la heroína y soñar, la aventura que podría definirse como interior, son dos actos que se funden y confunden a través de estrategias tanto explícitas como implícitas. se unen

Palabras clave: literatura infantil y juvenil, estrategias discursivas, viaje, sueños, fantasía épica.

\section{L'EXPÉRIENCE ONIRIQUE DANS LA LITTÉRATURE POUR LA JEUNESSE DE ROSA MONTERO}

Résumé: Cet article analyse le discours narratif de la trilogie de Rosa Montero, destinée aux enfants et aux jeunes: Las barbaridades de Bárbara, El viaje fantástico de Bárbara y Bárbara contra el Doctor Colmillos ${ }^{1}$.

L'objectif de cette recherche est de déterminer les techniques discursives utilisées dans ces trois œuvres où le voyage, l'aventure vécue par l'héroïne et "le rêve", l'aventure que l'on pourrait définir 1 Propuesta de traducción: Les barbaries de Barbara, Le voyage fantastique de Barbara et Barbara contre le Docteur Colmillos. 
comme intérieure, sont deux expériences qui se rejoignent et sont confondus à travers des stratégies explicites et implicites.

Mots clés: littérature pour enfants et jeunes, stratégies discursives, voyages, rêves, fantasy épique.

\section{ONEIRIC EXPERIENCES IN ROSA MONTERO'S CHILDREN'S AND YOUNG PEOPLE'S LITERATURE}

Abstract: This article analyses the narrative discourse in Rosa Montero's trilogy for children and young people: Las barbaridades de Bárbara, El viaje fantástico de Bárbara y Bárbara contra el Doctor Colmillos ${ }^{2}$. This research aims to determine the discursive strategies used in these three literary works where both travelling (the exterior adventure of the heroine) and dreaming (the adventure which could be defined as inner) are two different acts which melt and mingle through explicit and implicit strategies.

Keywords: Children's and Young People's Literature, discursive strategies, journey, dreams, epic phantasy.

En la trilogía de Rosa Montero destinada a un público infantil y juvenil: Las barbaridades de Bárbara (1ª ed. 1996), El viaje fantástico de Bárbara (1ª ed. 1997) y Bárbara contra el Doctor Colmillos ( $1^{\mathrm{a}}$ ed. 1998) viajar y soñar, especialmente en las dos últimas obras, son dos verbos que tienden a confundirse. Tras la lectura de esta trilogía al lector le asalta la duda sobre si los viajes de Bárbara, la heroína, fueron reales o soñados. Y es que, como María Victoria Sotomayor reflexiona sobre la realidad en su artículo "Personajes y temática en la Literatura Juvenil”: « ¿No es real lo que se sueña, imagina o desea? ¿Existen unas leyes únicas para determinar lo real?» (Sotomayor, 2006, p. 55).

¿Qué estrategias discursivas utiliza Rosa Montero para crear este viaje lector próximo a lo onírico?

\section{Las Barbaridades de Bárbara.}

Es en la primera obra de esta trilogía, Las barbaridades de Bárbara, donde más difícilmente se

2 Propuesta de traducción: Barbara’s Barbarities, Barbara's Fantastic Journey and Barbara against Doctor Colmillos. 
justifica la existencia tanto del viaje como del sueño, sin embargo nos encontramos ante un discurso que asienta las estrategias discursivas en las que el verbo viajar y soñar tenderán a la confusión y se desarrollarán en las dos obras posteriores de esta trilogía.

\subsection{Inclusión de elementos extraordinarios.}

Las Barbaridades de Bárbara es una obra de carácter realista y actual. Los espacios que recorren Bárbara y sus amigos son semejantes a los de cualquier preadolescente de clase media en una ciudad occidental, así como los conflictos a los que se enfrentan.

Sin embargo, ese mundo de carácter realista, actual y de fácil identificación con un lector joven contemporáneo, pierde en ocasiones la lógica convencional a través de la mirada de Bárbara, la heroína, que organiza la realidad que habita desde una perspectiva de lógica infantil o primitiva, introduciendo grados de subjetividad que podrían relacionarse con lo fantástico e incluyendo, en alguna medida, elementos extraordinarios al vincular ciertos personajes de carácter realista con personajes del cuento popular, como un dentista, al que Bárbara teme, y es definido como 'monstruo', comparado este con un ogro: «un día bajó furioso como un ogro» (Montero, 2008, p. 101); y su silla de dentista con el trono de una bruja: «Sí, sí, la reconocí enseguida: esa especie de sillón horrendo sólo podía ser el trono de una bruja o una silla de dentista» (Montero, 2008, p. 97). En el capítulo en el que aparece este personaje: El truco del deseo, este dentista se muda al edificio donde viven Bárbara y su familia y, como modo de darse a conocer, ofrece gratis una limpieza y revisión de boca a todos los niños menores de quince años hijos de los vecinos. Bárbara, que siente miedo de entrar a la consulta, desea con todas sus fuerzas que este inquilino desaparezca de la comunidad y acude al truco del deseo que le enseñó su abuela Sara: «Si deseas algo de verdad, y lo deseas con suficiente fuerza, lo conseguirás» (Montero, 2008, p. 94). Y es así como, efectivamente, el día que Bárbara acude a su cita con el dentista, encuentra a este mudándose porque el suelo del piso se ha hundido. La misma Bárbara ofrece una explicación de lógica convencional: «Y lo que había pasado es que una de las vigas de madera estaba podrida, porque la nuestra es una casa muy baja» (Montero, 2008, p. 102). Una explicación de lógica convencional compatible con la magia, como la propia Bárbara también afirma, dado que gracias al truco del deseo el dentista desaparece del vecindario: «Así es que fue una magia muy buena, muy poderosa. No es que funcione siempre, pero a veces desear da resultado» (Montero, 2008, p. 104). 


\title{
1.2 Regressus ad uterum.
}

En primer lugar, el sueño podría ser considerado como una forma de regressus ad uterum por su vinculación a un estado ‘alucinógeno’ similar al estado fetal, dado que el soñar “supone la devolución e integración del que sueña con el mundo de los objetos internos”(Bardavío, 1988, p. 63), sin intervención del mundo exterior. En relación a este regressus ad uterum que supone el estado del sueño ya aparece en Las Barbaridades de Bárbara, aunque mucho más debilitado, se trata de una alteración de conciencia provocada por la fiebre y justificada, de este modo, desde una lógica convencional.

\begin{abstract}
Llevo dos días en la cama con anginas. Ayer tuve mucha fiebre. Estar enferma es una cosa rara, a ratos te sientes muy mal y a ratos te sientes estupendamente. Quiero decir que hay momentos en los que te duele la cabeza, y te lloran los ojos, y parece como si te estuvieran apretando todo el cuerpo, es muy desagradable; pero en otros momentos te sientes bien, sólo un poco débil o perezosa o somnolienta. Y entonces es un gusto, porque la cama es como una cueva pequeñita y tú te acurrucas dentro de ella como un oso; y no vas al colegio y te compran tebeos y te hacen muchos mimos y te ponen la habitación medio a oscuras; y las sombras parecen personas o animales (Montero, 2008, p. 59).
\end{abstract}

En este fragmento no sólo apreciamos el estado ‘alucinógeno', de letargo o hibernación que puede suponer el sueño, sino también, y en segundo lugar, la inclusión de espacios simbólicos asociados a las 'fantasías intrauterinas' en los que se produce la transformación y nacimiento a una nueva conciencia. Bárbara, en la cama y medio a oscuras, se compara a sí misma con un oso acurrucado en su pequeña cueva.

En tercer lugar también aparece ya en esta primera obra de la trilogía ese regressus ad uterum en la repetición de lo semejante que, según reflexiones de Freud, «despierta sin duda la sensación de lo siniestro, que por otra parte nos recuerda la sensación de inermidad de muchos estados oníricos» (Freud, 1974, p. 2495). Una repetición de lo semejante tenuemente simbolizada en las gemelas Dina y Dani, compañeras de colegio de Bárbara exactamente iguales, generándole a la heroína cierta confusión:

Dina es la tercera de nuestro grupo y es muy amiga; pero tiene una hermana gemela, Dani, que es exactamente igual que ella, solo que Dani es malísima, y es un lío porque muchas veces las confundimos y porque a veces le haces una confidencia a Dina y luego resulta que era Dani y otras veces te enfadas con Dani y luego era Dina y así todo (Montero, 2008, p. 13).

Y, especialmente a este respecto, se asientan las bases de ese regressus ad uterum en la repetición de lo semejante presentándonos a dos personajes: Doria, el director del colegio de Bárbara y el dentista ya mencionado al que tanto teme la protagonista. Ambos personajes, en un principio de carácter 
realista, reaparecerán como autorreferencia textual en El viaje fantástico de Bárbara y Bárbara contra el Doctor Colmillos dotándolos de ciertas cualidades extraordinarias.

\subsection{Aperturas y finales.}

El final de esta obra, aunque no consideramos que llegue a provocar la sensación onírica de las otras dos obras que analizaremos a continuación, también consigue tambalear los límites de la realidad. ¿Qué es la realidad? ¿Es la realidad única e inmutable? Y el ser humano, ¿cómo construye la realidad? En el capítulo final, Las cosas no son como parecen, el discurso narrativo no ofrece una respuesta concreta a estas preguntas, pero invita a este tipo de reflexiones descubriéndose que Dani no era tan mala como se creía ni Dina tan buena; o que el Bestia, ese chico que parecía tenerle manía a Bárbara, en realidad estaba enamorado de ella. Las frases finales con las que se cierra esta obra transmiten, de manera explícita, desde el significado directo de la palabra, el mensaje que se pretende comunicar: «Ya digo que las cosas no son como parecen. Creo que es lo más importante que he aprendido en este curso» (Montero, 2008, p. 115).

¿Y el viaje? Efectivamente, y dado el carácter realista de esta obra, lo espacios que Bárbara y sus amigos recorren son espacios cotidianos y familiares, de corto recorrido, y que difícilmente pueden identificarse con la acción de viajar. En todo caso, y paradójicamente, en su primer capítulo, La huída, el discurso narrativo despega con la promesa de un viaje.

El martes pasado, Tulipa y yo decidimos escaparnos de casa. La idea se nos ocurrió después de leer una noticia en el periódico sobre tres niñas de nuestra edad que se habían marchado de Madrid y habían aparecido cuatro días después en Valencia... (Montero, 2008, p. 9).

Un viaje secreto entre Bárbara y su amiga Tulipa que, finalmente, y por la falta de discreción de esta última se convierte en el viaje masivo de toda la clase de Bárbara, 37 alumnos reunidos en una estación de trenes dispuestos a emprender viaje hacia Cercedilla cuando la profesora de matemáticas, la señora Martínez, los descubre e impide la huída. La promesa de un viaje que tan solo llega a ser un intento de fuga, «ni muy heroico ni muy aventurero» (Montero, 2008, p. 19), como la propia Bárbara lo describe. Sin embargo, y a través de este viaje frustrado, el discurso narrativo, en esta primera obra de la trilogía y, una vez más, asienta las bases e inicia a los lectores en las estrategias que los llevarán, junto a Bárbara y sus amigos, a ese viaje prometido, a esos viajes soñados. 


\section{El viaje fantástico de Bárbara.}

En la segunda obra de esta trilogía, el viaje y el sueño se vinculan de manera especialmente subrayada, así como se desarrollan las estrategias ya establecidas en Las barbaridades de Bárbara.

\subsection{Inclusión de elementos extraordinarios.}

Una de las estrategias fundamentales que utiliza esta obra para la inclusión de elementos extraordinarios es el género narrativo al que pertenece. Un género narrativo próximo a la fantasía épica que busca nuevos escenarios, acercándose a lo fantástico y misterioso, experimentando con «la anulación de fronteras entre realidad y fantasía en la obra de ficción» (Colomer, 2009, p. 203). En El viaje fantástico de Bárbara, rastreando los distintos niveles de realidad que se manifiestan en el género fantástico y observados por Jacqueline Held, se proyecta «un elemento común en un mundo extraordinario» (Held, 1981, p. 52). Bárbara y sus amigos, procedentes de un mundo realista, son proyectados por el discurso narrativo hacia El Otro Lado en busca de Canela, el perro de la heroína. El Otro Lado es un lugar fantástico de carácter épico, un mundo paralelo al real, compuesto por diferentes países en los que existen seres extraordinarios y acontecen situaciones insólitas que suscitan la sensación onírica.

\subsection{Regressus ad uterum.}

Otra estrategia destacable en El viaje fantástico de Bárbara, se encontraría vinculada a la inclusión de espacios simbólicos asociados a las 'fantasías intrauterinas' que se presentan a través de la caída en enormes agujeros negros «como la boca de una ballena» (Montero, 2007a, p. 28). Del mismo modo que la Alicia de Alicia en el País de las Maravillas cae por una madriguera hacia un mundo fantástico, así Bárbara y sus amigos caen por dos veces en esos agujeros y será en la segunda caída cuando, finalmente, aterricen en el País de los Muchos Miedos. « [...] caímos sobre algo blando y húmedo. Digo que era algo blando y húmedo porque todo estaba bastante oscuro y lleno de una niebla pegajosa» (Montero, 2007a, p. 79). En esta descripción no pasan inadvertidas las vinculaciones entre este espacio y el útero en el que se gesta una nueva vida: blando, húmedo y oscuro; un regressus ad uterum, un estado onírico provocado por el impulso tanático donde la angustia viene provocada, nos dice Freud (1974), por el retorno involuntario de lo reprimido. En el País de los Muchos Miedos los 
sueños se convierten en las pesadillas individuales de Bárbara y sus amigos, cobrando forma de arañas gigantes, arenas movedizas, enormes águilas y ratones contra los que tendrán que luchar. Fantasmas del inconsciente materializados con el fin de combatirlos y superarlos, siendo que los fantasmas en verdad son, como reflexiona Bardavío, «figuras cristalizadas, objetivadas y, así, reales de nuestras propias angustias» (Bardavío, 1988, p. 45).

En segundo lugar, aparecen personajes que saben o creen estar soñando dentro de la obra. Bárbara y sus amigos se encuentran a Doria en El Otro Lado, en el País de los No Queridos. Doria, el director del colegio de Bárbara, como hemos señalado ya había sido presentado en Las Barbaridades de Bárbara y reaparece en El Viaje Fantástico de Bárbara asegurando que él se encuentra en el mundo real, pero soñando que está en El Otro Lado: «Esto es un sueño, una pesadilla. Yo estoy dormido en mi cama y estoy soñando que estoy aquí» (Montero, 2007a, p. 103). Y Doria, irritado por el mal sueño e impaciente por despertar corre a una cabina telefónica y marca su propio número: «-¡Venga! ¡Despierta de una vez! ¿Estás sordo? ¿No oyes el teléfono? ¡Despierta! -gruñía frenético» (Montero, 2007a, p. 104). Esta estrategia discursiva nos remite a lo siniestro a través de dos claves esenciales: Por un lado ese regressus ad uterum que supone el estado del sueño como un estado 'alucinógeno' similar al estado fetal donde se materializan nuestros fantasmas y, por otro lado, la repetición de lo semejante que, según reflexiones de Freud ya citadas, activa la sensación de lo siniestro. En la situación ejemplificada nos encontramos ante el desvanecimiento de los límites entre realidad y ficción, un espacio indefinido e inestable que puede hacerle caer al joven lector en la desorientación o el sin sentido y es sin embargo lo incongruente, como advierte Gabriel Janer Manila, lo absurdo de la situación, lo que al mismo tiempo sitúa al receptor en un contexto lúdico, facilitándose la superación de la angustia que provoca la regresión.

La incongruencia nos provoca la risa porque nos sorprende y contiene por definición la idea de sorpresa. Incongruencia y sorpresa son dos aspectos de una experiencia emocional y cognitiva. El niño es capaz de percibir el carácter lúdico de la representación cómica: de la incongruencia. Fuera del contexto lúdico, seguramente, la misma incongruencia puede producirle malestar. (Janer Manila, 1996, p. 17)

\subsection{Aperturas y finales.}

La sensación onírica se intensifica cuando Bárbara, al final de la obra, despierta en su cama y su 
madre le asegura que la aventura experimentada en El Otro Lado fue un sueño; entonces la heroína se interroga si no tendría razón Doria «y nos habíamos metido en su pesadilla» (Montero, 2007a, p. 110). El sueño dentro del sueño, recurso metaficcional muy similar al de Alicia en A través del espejo cuando Patachunta y Patachún le informan a la niña de que el Rey Rojo está soñándola: « ¡Vamos, tú no eres más que un objeto soñado por él!» (Carroll, 1999, p. 224)

\section{Bárbara contra el Doctor Colmillos.}

En la tercera obra de esta trilogía, Bárbara contra el Doctor Colmillos, viajar y soñar son acciones que también se confunden e hibridan de manera subrayada.

\subsection{Inclusión de elementos extraordinarios.}

La inclusión de elementos extraordinarios la facilita, del mismo modo que en El viaje fantástico de Bárbara, el género fantástico al que pertenece esta obra, próximo a la fantasía épica. Siguiendo con las investigaciones de Jacqueline Held en Bárbara contra el Doctor Colmillos, los niveles de la realidad se alteran con la «intrusión de un elemento extraordinario en un mundo común» (Held, 1981, p. 50). El Doctor Colmillos es un malvado dentista y, por la autorreferencia textual que remite a la primera obra de esta trilogía, el lector sabe que Bárbara teme a ese gremio. Este personaje agresor, el Doctor Colmillos, proviene de El Otro Lado e ingresa en el mundo realista de la protagonista trayendo con él el caos y una constante de elementos extraordinarios: los seres humanos quedan paralizados y los animales y objetos adquieren cualidades humanas. Al comienzo de la obra el discurso narrativo presenta ese universo de carácter realista con el que el lector podrá identificarse de manera directa, sin embargo paulatinamente y por efecto del caos que porta el Doctor Colmillos, ese mundo fácilmente identificable se irá transformando a través de situaciones calificadas, por la propia Bárbara, como 'raras'. Situaciones que perturban el orden conocido y que progresivamente irán aumentando el grado de incongruencia hasta el punto de obstaculizarle al lector un encuentro con el sentido a través de la lógica convencional. Bárbara y sus amigos recorren espacios de su propia ciudad buscando las Puertas que conectan con El Otro Lado, abiertas por el Doctor Colmillos y por las que avanza el caos amenazando de muerte a sus habitantes; así como también huyen de este agresor que intentará evitar que los héroes cierren esas Puertas. Pero, ¿y el viaje? ¿Cómo podríamos entender que Bárbara y sus 
amigos viajan si los espacios que recorren son los cotidianos de su propia ciudad como es el caso de una biblioteca, un colegio o El Corte Inglés? En primer lugar la sensación de viaje es provocada por la aventura que representa la búsqueda de esas Puertas y el combate de peligro mortal contra el caos y el Doctor Colmillos; en segundo lugar esta sensación de viaje se intensifica por la transformación caótica de esos espacios familiares que se alejan de lo conocido, elementos extraordinarios irrumpiendo en lo cotidiano que ocupan una doble función en esta obra: llevar a la experiencia del viaje y, utilizando las palabras literales del discurso narrativo, generar «una sensación rarísima, como de sueño» (Montero, 2007b, p. 85).

\subsection{Regressus ad uterum.}

La inclusión de espacios simbólicos vinculados a las 'fantasías intrauterinas' se reiteran en Bárbara contra el Doctor Colmillos a través de esas Puertas abiertas al caos que intentarán succionar a los que pretendan cerrarlas, agujeros que llevan a El Otro Lado. Aunque en esta ocasión la caída no llegará a producirse y esos agujeros, ya no negros si no de "brillo cegador", de carácter más mortal que transformador, suscitan la comparación con el túnel al final del cual se encuentra la muerte-luz de nuestro imaginario colectivo.

\footnotetext{
Cerrar las Puertas es peligroso y difícil. Cuando apretemos el botón, la Puerta intentará chuparnos y trasladarnos al Otro Lado. [...] De pronto [...] se abrió un agujero de brillo cegador. Era como estar mirando al interior de un rayo: la luz era así de eléctrica, y de intensa, y de peligrosa. Un viento increíble empezó a chuparnos hacia el agujero. Nosotros intentábamos agarrarnos a todas partes de alguna manera, pero estaba claro que no podríamos aguantar mucho tiempo: yo sentía cómo se me arrancaban los pelos de las cejas, de lo mucho que aspiraba el pozo luminoso (Montero, 2007b, p. 50).
}

La sensación onírica se intensifica en esta obra a través de una estrategia explícita semejante a la ya mencionada en El viaje fantástico de Bárbara, la inclusión de personajes en estado de letargo o inconsciencia. Una regresión simbólica hacia un estado anterior a la conciencia, un sueño estrechamente asociado a espacios vinculados a las 'fantasías intrauterinas'. El caos, en Bárbara contra el Doctor Colmillos, no solo altera el comportamiento de los habitantes de la ciudad de la heroína, si no que en su grado más avanzado, provoca cambios físicos en todos ellos, como la petrificación: « [...] no te lo podrás creer, pero toda la gente del diario estaba paralizada y petrificada, endurecida y de color blanquecino, como si fueran estatuas» (Montero, 2007b, pp. 18-19); o el sueño en el que cae el padre 
de Bárbara, un sueño que el discurso narrativo compara, en referencia intertextual, con el de La Bella Durmiente: «Entonces, en mi pena y mi apuro, recordé aquel cuento de cuando era pequeña... esa Bella Durmiente que despierta cuando la besan. Y besé a mi padre en la mejilla, despacito» (Montero, 2007b, p. 21-22); o la inactividad de mujeres, hombres y niños inertes como maniquíes que llenan los armarios de El Corte Inglés, personas que no están muertas, «porque respiraban y a veces parpadeaban; pero daba miedo verlas, tan insensibles y calladas» (Montero, 2007b, p. 92). Seres humanos inmóviles que esperan a que trajes y todo tipo de ropa, que «se comportaba igual que si estuviera viva y sólo le faltara la persona de dentro» (Montero, 2007b, p. 86), los compraran. Activándose de este modo y, en alguna medida, esa emoción de lo siniestro, «algo reprimido que retorna» (Freud, 1974, p. 2498) y que supone, como nos indica Freud, una confusión de lógica primitiva o infantil, y de los primeros años de juego del ser humano en los que «no suele trazar un límite muy preciso entre las cosas vivientes y los objetos inanimados» (Freud, 1974, p. 2493).

\subsection{Aperturas y finales.}

El comienzo y final de la tercera obra de esta trilogía utiliza una estrategia más, que intensifica la sensación onírica, se trata de la rememoración. ¿Es fiable la memoria? ¿Qué grado de imaginación supone recordar? Y si perdemos la memoria, ¿no entramos de algún modo, y en alguna medida, en cierto grado de inconsciencia?

Encontramos en el comienzo de Bárbara contra el Doctor Colmillos una prolepsis inicial, a modo de sumario, en la que se apela directamente a la memoria del lector y se le incita a generar el espejismo de que las aventuras que a continuación leerá ya las ha vivido anteriormente junto a la heroína y serán una rememoración común.

\footnotetext{
De manera que hoy es un día bastante feo; pero de todas formas lo prefiero a todo lo que sucedió cuando los Días del Caos, este verano, cuando el mundo se volvió al revés y las Puertas se abrieron, y empezó a perseguirnos el Doctor Colmillos. ¿No lo recuerdas? Pasaron cosas tremendas, aventuras horripilantes y estupendas, pesadillas de verdad y no del libro (Montero, 2007b, p. 8).
}

Pero, lógicamente, el lector no recuerda nada, llevándole el discurso narrativo a la ilusión de un estado semejante a la amnesia donde la sensación onírica del viaje lector que va a recorrer le alcanza a él mismo. Pero no es solo el lector el que padece amnesia, nadie, excepto Bárbara y sus amigos, recuerdan la amenaza mortal de los Días del Caos, todos los habitantes de la ciudad de la 
heroína quedaron, como ya se ha indicado, petrificados o sumidos en el sueño y despertaron una vez restablecido el orden. Cuando Bárbara hablaba de lo sucedido ellos le tocaban «la frente por si tenía fiebre» (Montero, 2007b, p. 140), por si estuviera delirando o soñando.

La prolepsis inicial se recupera en autorreferencia textual al final de la historia: « ¿No te suena lo que acabo de contarte? ¿Tú tampoco te acuerdas? Pues todo sucedió como yo te lo he dicho» (Montero, 2007b, p. 143).

En este final de sentido circular y a través de esta estrategia metaficcional, el discurso narrativo incluye al lector en la misma aventura vivida por la heroína, ya no como experiencia lectora o experiencia 'de escucha', sino como vivencia 'real', debilitando los límites entre realidad/ficción, realidad/sueño. «¿No me crees?» (Montero, 2007b, p. 143), insiste la voz narradora apelando directamente al lector.

\section{Conclusiones.}

Comenzábamos este artículo preguntándonos acerca de cuáles son las estrategias discursivas que utiliza Rosa Montero para crear este viaje lector próximo a lo onírico.

Observar la realidad a través de la lógica infantil o primitiva de una niña, permite la inclusión de elementos extraordinarios y también ayuda a percibir cualquier recorrido, en principio cotidiano, como un viaje mágico y apasionante. Si esta estrategia es utilizada en un discurso narrativo próximo a la fantasía épica, la sensación onírica se intensifica, dado que este género no sólo facilita, incluso exige, la incorporación de elementos fantásticos; así como lo extraordinario del viaje se encuentra subrayado por el riesgo extremo que este conlleva, combates de peligro mortal en situaciones insólitas y agresores inusuales.

Las diferentes formas de regressus ad uterum favorecen la sensación onírica y aportan al viaje exterior del héroe la impresión simultánea de un viaje interior. En esta trilogía nos encontramos, en primer lugar, con espacios simbólicos asociados a las 'fantasías intrauterinas' que habitan los personajes y donde se produce la transformación, la gestación a una nueva conciencia. Por otro lado, también observamos la repetición de lo semejante o los regresos involuntarios a una misma situación, activándose la sensación de lo siniestro. Simbólicamente se trata de lo reprimido que retorna generando angustia, son los fantasmas del inconsciente contra los que se lucha en un viaje que es al mismo tiempo interior y exterior. Por último los personajes atraviesan estados de sueño, letargo, petrificación, 
amnesia, febriles... en los que pierden la conciencia o se ve alterada, modificándose la percepción de la realidad.

Para finalizar se encuentran aquellas estrategias discursivas que incorporan al lector en el discurso narrativo de manera más o menos explícita, rompiendo con los límites entre realidad y ficción: apelaciones directas a través de preguntas retóricas, ilusión de memoria común mediante autorreferencias textuales que retoman situaciones o personajes o, más explícitamente, el espejismo de experiencias compartidas entre personajes ficcionales y receptor, como es el caso de la amnesia sufrida por todos los habitantes de la ciudad de Bárbara, incluido el lector, cuando fueron amenazados de peligro mortal por el caos del Doctor Colmillos.

\section{Referencias bibliográficas}

Bardavío, J. M. (1988). Fantasías uterinas en la literatura norteamericana. Zaragoza: Prensas de la Universidad de Zaragoza.

Carrol, Lewis; Gardner, Martin (1999). Alicia Anotada. Madrid: Ediciones Akal.

Colomer, T. (2009). Entre la literatura y las pantallas: el auge de la fantasía épica en Teresa Colomer (coord.). Lecturas adolescentes, 197-219.

Freud, S. (1974). Obras Completas. Tomo VII. Madrid: Editorial Biblioteca Nueva.

Held, J. (1981). Los niños y la literatura fantástica. Función y poder de lo imaginario. Barcelona: Ediciones Paidós Ibérica, S.A.

Janer Manila, G. (1996). Humor y representación cómica de la realidad: comicidad y literatura. Peonza, $38,16-18$.

Montero, R. (2008). Las barbaridades de Bárbara. Madrid: Alfaguara Infantil.

Montero, R. (2007a). El viaje fantástico de Bárbara. Madrid: Alfaguara Infantil.

Montero, R. (2007b). Bárbara contra el Doctor Colmillos. Madrid: Alfaguara Infantil.

Montero, R. (2004). El nido de los sueños. Madrid: Siruela.

Montero, R. (1999). Bella y Oscura. Barcelona: Editorial Seix Barral.

Sotomayor, M. V. (2006). Personajes de la literatura juvenil: cambio y maduración, en María Victoria Sotomayor Sáez (coord.) Personajes y temáticas en la Literatura Juvenil. Aulas de verano, 5372. 